\title{
Impact of Ovarian Hormones on the Modulation of the Serotonin Transporter by Fluvoxamine
}

\author{
Saloua Benmansour*,', Jonathan P Piotrowski', Alfonso V Altamirano' and Alan Frazer ${ }^{1,2}$ \\ 'Department of Pharmacology, University of Texas Health Science Center at San Antonio, San Antonio, TX, USA; ${ }^{2}$ South Texas Veterans Health \\ Care System, San Antonio, TX, USA
}

\begin{abstract}
Most preclinical studies examining the mechanism(s) of action of antidepressants are carried out using male animals. Blockade of serotonin transporter (SERT) function by selective serotonin reuptake inhibitors (SSRIs) is the initial event that triggers a not completely understood process that results in clinical improvement in depression. To investigate whether there are differences in the ability of SSRIs to inhibit the SERT between male and female rats at different phases of the estrous cycle, clearance of locally applied serotonin (5-HT) was measured by in vivo chronoamperometry. Local application of the SSRI, fluvoxamine, directly into the CA3 area of hippocampus increased significantly 5-HT clearance time parameters in male rats and female rats in estrus or diestrus, but not in proestrus. The contribution of ovarian steroids to this result was investigated in ovariectomized (OVX) rats treated with estradiol benzoate (EB) and/or progesterone $(\mathrm{P})$. In OVX-control rats, fluvoxamine increased clearance time parameters, whereas EB and/or P treatment blocked this effect, consistent with what was seen in female rats in proestrus. This effect was gender-specific, since treatment of castrated rats with EB/ $P$ had no effect on the ability of fluvoxamine to slow 5-HT clearance. The time course of hormonal effects showed that I-60 min after local application of $17-\beta$-estradiol $\left(E_{2}\right)$ into the CA3 region of OVX rats, fluvoxamine had no effect on clearance time of 5-HT. $E_{2}-B S A$ mimicked $E_{2}$ 's effects at 10 min but not at 60 min. Pretreatment with estrogen receptor antagonists blocked the effects of $E_{2}$. The finding that acutely both estradiol and progesterone can inhibit the ability of an SSRI to slow the clearance of 5-HT, may have important implications for the use of SSRIs in women.

Neuropsychopharmacology (2009) 34, 555-564; doi: I0. I038/npp.2008.23; published online 5 March 2008
\end{abstract}

Keywords: serotonin transporter; estradiol; progesterone; fluvoxamine; chronoamperometry; hippocampus

\section{INTRODUCTION}

Depression is more common in females than males (Kessler, 2003) and in women, may be more common at times of low estradiol levels (Fink et al, 1996; Halbreich et al, 1992; Pearlstein, 1995). Depressive episodes in women may be more recurrent, longer in length, and associated with more functional impairment than those in men (Burt and Stein, 2002; Yonkers, 2003). In spite of this, preclinical data examining the effects of antidepressants (ADs) on either behavioral, physiological, or neurochemical parameters, have mainly used males subjects until recently. Pharmacological interventions involving estrogens (and/or progesterone) in depressed women have been proposed to correct presumed steroid hormone deficiencies or fluctuations. Hormonal (or estrogen alone) therapy has also been reported to have $\mathrm{AD}$ effects in perimenopausal and

\footnotetext{
*Correspondence: Dr S Benmansour, Department of Pharmacology (MC 7764), University of Texas Health Science Center at San Antonio, 7703 Floyd Curl Drive, San Antonio, TX 78229-3900, USA, Tel: + I 210567 4203; Fax: + I 210567 4303;

E-mail: benmansour@uthscsa.edu

Received 5 September 2007; revised 10 January 2008; accepted 28 January 2008
}

postmenopausal women (Zweifel and O’Brien, 1997; Soares et al, 2001; Huttner and Shepherd, 2003), although this has not been a universal finding (Saletu et al, 1995). Premenopausal depressed women may have better response to selective serotonin reuptake inhibitors (SSRIs) than to tricyclic ADs (Kornstein et al, 2000). However, other studies did not confirm these findings (Quitkin et al, 2002; Scheibe et al, 2003). Adjunctive treatment with estrogen in addition to an SSRI may be beneficial in depressed menopausal patients (Yonkers, 2003), although, again, this has not been found in all studies (Huttner and Shepherd, 2003). For multiple reasons, SSRIs are the treatment of choice for depression during perimenopause and menopause.

Blockade of serotonin transporter (SERT) function by SSRIs is the initial event that triggers a still not completely understood process that results in clinical improvement after repeated treatment (Lenox and Frazer, 2002). Reports analyzing the action of estrogen in vivo on SERT uptake sites and mRNA levels are inconclusive. Increases, decreases, and no change have been reported (Attali et al, 1997; Bethea et al, 1998; Krajnak et al, 2003; McQueen et al, 1997; Mendelson et al, 1993, Pecins-Thompson et al, 1998, Zhou et al, 2002). Discrepancies in these studies may be explained by variability in the treatment paradigm used, 
such as the time elapsed between ovariectomy and estrogen treatment, the duration of estrogen treatment, and the brain region evaluated.

Estrogen receptors (ER) as well as progesterone receptors are members of the superfamily of hormone-regulated nuclear receptors. Depending on the onset and duration of the effect, ovarian hormones can act either by a genomic mechanism, using classical nuclear transcription factor receptors (Katzenellenbogen, 2000), or by a non-genomic, less well-characterized, membrane signaling mechanism (Kelly et al, 1999; Nadal et al, 2000). The genomic pathway requires at least $30-60 \mathrm{~min}$ for its effects to manifest and is associated with changes in protein synthesis. However, the 'nuclear hormone receptors' are not restricted to the nucleus; they can be found within the nucleus, cytoplasm, and in the cell membrane. It has more recently become clear that estrogen can elicit rapid, within seconds to minutes, signaling events that are not mediated by classical genomic pathways. Steroid-bovine serum albumin (BSA) conjugates have become useful tools to study the membrane-mediated action of steroids, since they are biologically active and do not penetrate the plasma membrane of the cell readily (Blackmore and Lattanzio, 1991; Ramirez and Zheng, 1996).

To begin providing a comprehensive understanding of how hormones such as estrogen or progesterone influence the effect of SSRIs, it is important to determine whether they alter their inhibitory effect on the SERT. This study describes how SSRIs acutely affect SERT function in female rats in comparison with the effects observed in male rats, and how ovarian hormones influence these effects. SERT function was measured by in vivo chronoamperometry in female rats at different stages of the estrous cycle, as well as in ovariectomized (OVX) rats treated with estradiol and/or progesterone. The time course of the effects caused by local administration of 17 - $\beta$-estradiol $\left(\mathrm{E}_{2}\right), \mathrm{E}_{2}-\mathrm{BSA}$, and $\mathrm{ER}$ antagonists was also investigated.

\section{MATERIALS AND METHODS}

\section{Animals}

Intact females, OVX females, intact males, or castrated males (all Sprague-Dawley rats; 250-350 g, Harlan, Indianapolis, IN) were housed on a 12:12 h light/dark cycle with lights on at $0700 \mathrm{~h}$ and with food and water provided ad libitum. All animal procedures were in strict accordance with the National Institutes of Health Guide for Care and Use of Laboratory Animals, and were approved by the local Institutional Care and Use Committee. All efforts were made to minimize both the number of animals used and stress or discomfort to the animal during the experimental procedure.

Female rats are sexually mature at about 8-9 weeks and weigh about $200 \mathrm{~g}$ at that age. Vaginal smears in intact female rats were monitored daily for the presence of predominantly nucleated cells (proestrus), cornified cells (estrus), or leukocytes (diestrus). Only females showing four consecutive regular estrous cycles (4-5 days) were used in these studies. Classification of the estrous cycle was based on the vaginal smear on the day of the experiment and the prior vaginal smear history. For comparison purposes, male rats were also studied. OVX and castrated rats were allowed a 2- to 3-week recovery after surgery, before starting treatment, in order to provide time for endogenous hormones to decline and the animals to adapt to their loss.

\section{Hormone Treatments}

Because circulating amounts of $\mathrm{E}_{2}$ do not remain elevated for very long after systemic injection of $E_{2}$, a slower-release esterified form of $E_{2}$, namely estradiol benzoate (EB), was used for this part of the study. The treatment paradigm was chosen to achieve estrogen and progesterone plasma levels that were similar to those characterized in proestrus (Gibbs, 1996). For combination treatment, EB $(25 \mu \mathrm{g}$ in $100 \mu \mathrm{l}$ peanut oil; Sigma-Aldrich, St Louis, MO) was administered subcutaneously to OVX or castrated rats, followed $48 \mathrm{~h}$ later by subcutaneous injection of progesterone $(\mathrm{P}, 500 \mu \mathrm{g}$ in $100 \mu l$ peanut oil; Sigma-Aldrich). The experiments were carried out $24 \mathrm{~h}$ after administration of $\mathrm{P}$. When given separately, the hormones were administered at these doses with the experiments carried out $72 \mathrm{~h}$ after administration of EB or $24 \mathrm{~h}$ after P. Control OVX rats received peanut oil injections.

\section{In Vivo Chronoamperometry}

Chronoamperometric recordings were carried out in vivo in the CA3 region of the hippocampus as described previously (Benmansour et al, 1999, 2002). Multi-barrel micropipettes were filled with either 5-HT $(200 \mu \mathrm{M}$; Sigma Chemicals Co., St Louis, MO), fluvoxamine $(400 \mu \mathrm{M}$; Pharmacia and Upjohn, Kalamazoo, MI), citalopram $(400 \mu \mathrm{M}$; Forest Laboratories, Jersey City, NJ), $\mathrm{E}_{2}$ (dissolved in PBS containing ethanol at a final concentration less than $0.0001 \%$; Sigma-Aldrich), ICI 182,780, or tamoxifen (Tocris, Ellisville, $\mathrm{MO})$, or $\beta$-estradiol 6-(O-carboxymethyl)oxime:BSA $\left(\mathrm{E}_{2}-\right.$ BSA; Sigma-Aldrich). The latter was filtered as described by Stevis et al (1999), using a Microcon cartridge with a 3-kDa cut-off (Amicon, Beverly, MA) to eliminate any free $\mathrm{E}_{2}$ from the $\mathrm{E}_{2}-\mathrm{BSA}$ solution. 5-HT was delivered by pressure ejection. After obtaining reproducible electrochemical signals to $5-\mathrm{HT}$, the ability of fluvoxamine or citalopram (four times the amount of 5-HT applied) to block 5-HT clearance was measured by its local application 60-90 s before pressure ejection of 5-HT. High-speed chronoamperometric recordings were made using the Fast-12 system (Censet, Lexington, KY).

Several parameters are obtained from the electrochemical signal produced by exogenous applications of 5-HT. Shown in this study is clearance time parameter, $T_{80}$, which is the time required for the peak amplitude to be reduced by $80 \%$. Also analyzed in this study is clearance rate, $T_{C}$, which is based on the slope of the initial pseudolinear (from $\mathrm{T}_{20}$ to $\mathrm{T}_{60}$ ) portion of the decaying signal (Zahniser et al, 1999).

\section{Autoradiographic Procedures}

Serotonin uptake sites were detected using $\left[{ }^{3} \mathrm{H}\right]$ cyanoimipramine ([$\left.\left.{ }^{3} \mathrm{H}\right]-\mathrm{CN}-\mathrm{IMI}\right)$ (Benmansour et al, 1999, 2002). Brain sections $(20 \mu \mathrm{m})$ were incubated with $1 \mathrm{nM}\left[{ }^{3} \mathrm{H}\right]-\mathrm{CN}-$ IMI (80-85 Ci/mmol; American Radiolabeled Chemicals Inc., St Louis, MO) for $24 \mathrm{~h}$ at $4{ }^{\circ} \mathrm{C}$ in a buffer containing $50 \mathrm{mM}$ Tris ( $\mathrm{pH}$ 7.4) and $150 \mathrm{mM} \mathrm{NaCl}$. Non-specific 
binding was defined using $5 \mu \mathrm{M}$ sertraline, and was approximately $5 \%$ of total binding. Following incubation, sections were washed in buffer for $60 \mathrm{~min}$ at $4^{\circ} \mathrm{C}$ and were then dipped in distilled water. Dried, slide-mounted sections and calibrated $\left[{ }^{3} \mathrm{H}\right]$ standards (American radiolabelled Chemicals Inc.) were placed into spring-loaded cassettes and apposed to tritium-sensitive film, Kodak Biomax MR (Kodak, Rochester, NY) at room temperature for 6 weeks. Optical densities of brain images were converted to femtomoles per milligram protein using the NIH-IMAGE software. Measurements were taken at the level of plate 30 of the atlas of Paxinos and Watson (1986).

\section{Homogenate-Binding Procedures}

The binding of $\left[{ }^{3} \mathrm{H}\right]$ citalopram to hippocampal membranes was determined according to the method developed by D'Amato et al (1987), with a few modifications. In brief, rats were decapitated and the hippocampus was dissected out and homogenized in $25 \mathrm{ml}$ of ice-cold buffer ( $50 \mathrm{mM}$ Tris$\mathrm{HCl}, 120 \mathrm{mM} \mathrm{NaCl}$, and $5 \mathrm{mM} \mathrm{KCl}, \mathrm{pH} \mathrm{7.4).} \mathrm{The} \mathrm{homo-}$ genate was centrifuged at $30000 \mathrm{~g}$ for $10 \mathrm{~min}$ at $4^{\circ} \mathrm{C}$. The resulting pellet was resuspended in buffer and centrifuged again twice. The homogenate was incubated with a saturating concentration of $\left[{ }^{3} \mathrm{H}\right]$ citalopram $(5 \mathrm{nM}, 72 \mathrm{Ci} /$ mmol; PerkinElmer, Boston, MA) for $75 \mathrm{~min}$ in the absence or presence of fluvoxamine $\left(3 \times 10^{-10}-1 \times 10^{-6} \mathrm{M}\right)$ at $24^{\circ} \mathrm{C}$ in a final volume of $500 \mu$ l. Incubation was terminated by adding ice-cold buffer and filtration through Whatman GF/ B filters (pretreated with $0.1 \%$ polyethylenamine) using a 24-channel cell harvester. Radioactivity trapped in the filters was measured using a Packard 1900 TR liquid scintillation counter. Protein content was determined by the method of Bradford (1976). A non-linear regression fit of the data using the Graphpad Prism Software (Intuitive Software for Science, San Diego, CA) allowed to determine the $\mathrm{IC}_{50}$ values and calculate the inhibition constants $K_{\mathrm{i}}$ according to the Cheng-Prusoff equation. The $K_{\mathrm{d}}$ value used in this study to calculate $K_{\mathrm{i}}$ was determined from saturation binding data for $\left[{ }^{3} \mathrm{H}\right]$ citalopram $(0.1-10 \mathrm{nM})$ in hippocampal membranes prepared from male or female rats in proestrus. $K_{\mathrm{d}}$ values (average of three independent experiments for each group, each performed in triplicate) for $\left[{ }^{3} \mathrm{H}\right]$ citalopram binding to the SERT were similar in male rats $(0.87 \pm 0.10 \mathrm{nM})$ or females in proestrus $(0.93 \pm 0.09 \mathrm{nM})$. Therefore, an average value for $K_{\mathrm{d}}$ of $0.9 \mathrm{nM}$ was used to calculate $K_{\mathrm{i}}$ for all the groups.

\section{Hormones Levels}

OVX rats were treated with $\mathrm{EB} / \mathrm{P}$ or vehicle as described above in the hormone treatment section. Trunk blood was collected ( $72 \mathrm{~h}$ after administration of EB or $24 \mathrm{~h}$ after $\mathrm{P}$ ) for measurement of hormone levels in serum by radioimmunoassay (RIA). Estradiol concentrations in rat serum were determined by RIA of duplicate samples using the DSL ultrasensitive estradiol RIA kit (DSL-4800), according to the manufacturer's instructions; progesterone concentrations in the rat serum were determined by RIA of duplicate samples using the DSL progesterone-coated tube RIA kit (DSL-3900) according to the manufacturer's protocol (Adams et al, 2001; Gore et al, 2000).

\section{Statistical Analysis}

Data were analyzed by $t$-test or one-way ANOVA followed by Newman-Keuls post hoc multiple comparisons, with significance determined at $p<0.05$.

\section{RESULTS}

\section{Effect of Fluvoxamine on SERT Function During the Estrous Cycle}

The first experiment was designed to examine the ability of fluvoxamine to inhibit SERT function in female rats in diestrus, proestrus, and estrus in comparison with the effects observed in male rats. A representative 5-HT signal generated by local application of exogenous serotonin in the CA3 region is shown in Figure 1. As expected, fluvoxamine prolonged the clearance time of 5-HT in male rats (Benmansour et al, 1999, 2002). By contrast, in female rats in proestrus, local application of fluvoxamine did not prolong the clearance time of 5-HT. The effect of fluvoxamine on the 5-HT clearance time parameter, $T_{80}$, in males, or in females in proestrus, estrus, or diestrus, is shown in Figure 2a. In male rats, as well as in female rats in estrus or diestrus,
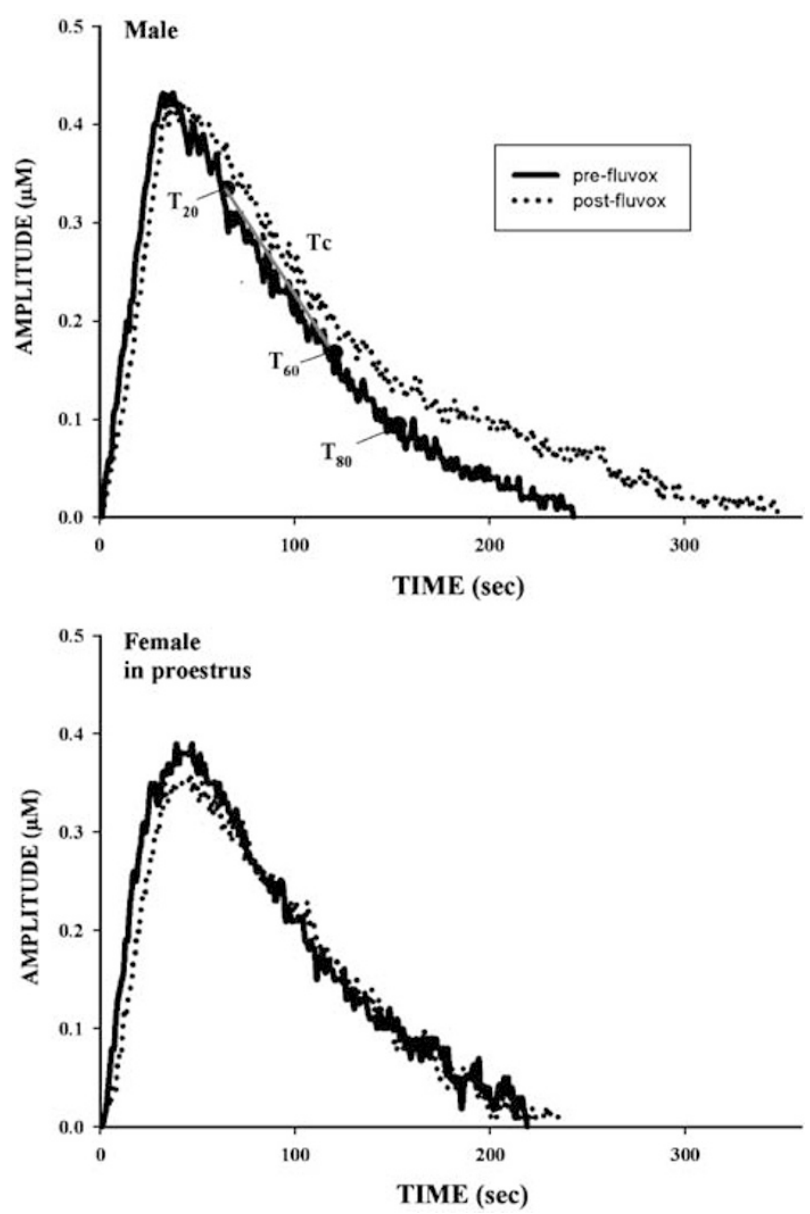

Figure I Representative 5-HT electrochemical signals illustrating the effect of locally applied fluvoxamine in the CA 3 region of hippocampus of a male rat or a female rat in proestrus. The signal was generated by local application of 5-HT (2.6-10 pmoles). Fluvoxamine (4 $\times$ the amount of 5$\mathrm{HT}$ ) was pressure-ejected $60-90 \mathrm{~s}$ before the next application of 5-HT. For clarity, only oxidation signals are shown. 

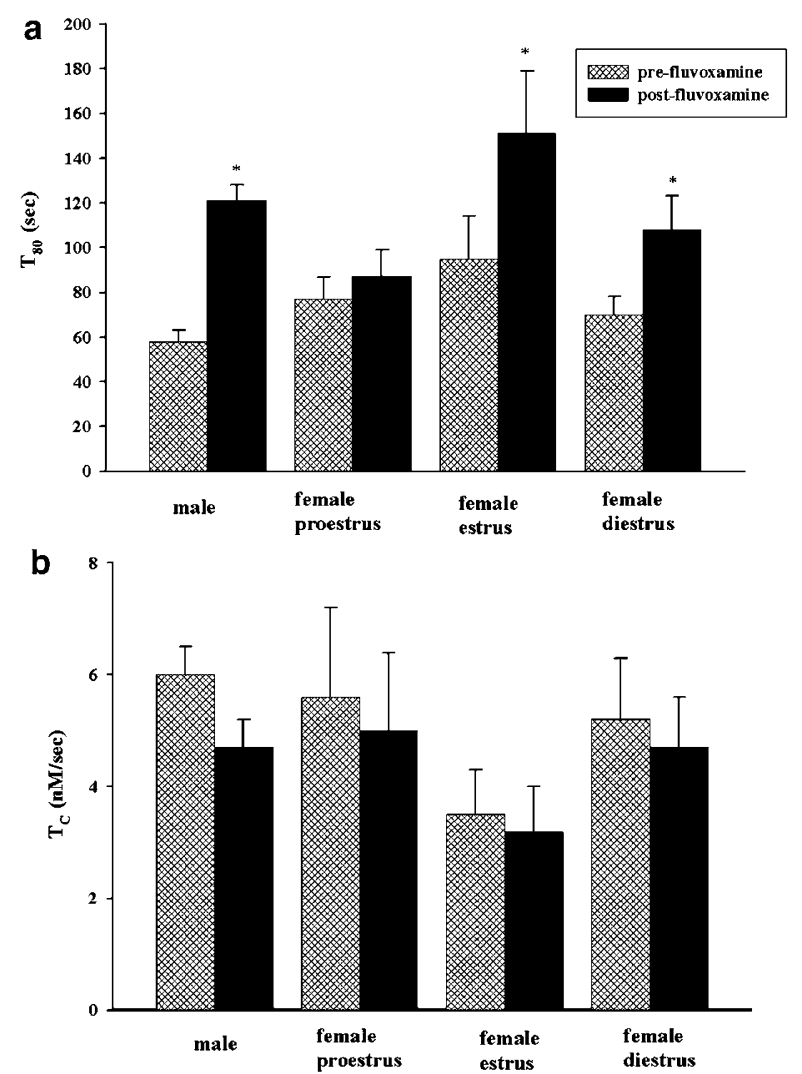

Figure 2 Effects of fluvoxamine on the clearance time, $T_{80}$, and the clearance rate, $T_{C}$, in male and female rats at different stages of the estrous cycle. Electrochemical recordings were carried out in the CA3 region of dorsal hippocampus of male rats or female rats in proestrus, estrus or diestrus. Fluvoxamine was pressure-ejected $60-90$ s before the second application of $5-H T$. (a) Bars and brackets represent mean $T_{80}$ value (in sec) before and after fluvoxamine application; \pm SEM $(n=8-10)$. (b) Bars and brackets represent mean $T_{C}$ value (in $\mathrm{nM} / \mathrm{s}$ ) before and after fluvoxamine application; \pm SEM $(n=8-10) . * p<0.05$, paired Student's t-test comparing pre-fluvoxamine value with post-fluvoxamine value for each group. The amount of 5-HT ejected was adjusted so as to obtain comparable signal amplitudes $(0.25-0.4 \mu \mathrm{M})$ in the various groups of animals. This approach enables clearance rates to be compared easily among the treatment groups, as clearance rate is dependent on signal amplitude. Consequently, the volume (and therefore the amount) of 5-HT was varied. The mean amount of $5-\mathrm{HT}$ in pmoles \pm SEM pressure ejected in each group was not significantly different between groups and was as follows: male, $6.3 \pm 3$; female proestrus, 14.7 \pm 4 ; female estrus, $10.0 \pm 3$; and female diestrus, $7.2 \pm 2$. Fluvoxamine was always given at four times the amount of $5-\mathrm{HT}$ applied. There were no significant correlations between the volume of 5 HT ejected and fluvoxamine-induced effects on the $T_{80}$ parameter (data not shown). Thus, whether fluvoxamine had an effect or not, was independent of the volume (or amount) of 5-HT ejected.

fluvoxamine slowed clearance of 5-HT, as demonstrated by a significant increase in $T_{80}$ value. By contrast, in female rats in proestrus, the inhibitory effect of fluvoxamine on clearance time was abolished. The clearance rate, $T_{\mathrm{C}}$ did not changed significantly upon local application of fluvoxamine in males or females at any stage of the cycle (Figure $2 \mathrm{~b}$ ).

\section{SERT Density and Affinity for Fluvoxamine During the Estrous Cycle}

The density of SERT binding sites was measured in the same rats using quantitative autoradiography of $\left[{ }^{3} \mathrm{H}\right]-\mathrm{CN}-$
Table I $\left[{ }^{3} \mathrm{H}\right]-\mathrm{CN}-\mathrm{IMI}$ Binding in Males and Females Rats at Different Phases of the Estrous Cycle

\begin{tabular}{lccc}
\hline Groups & \multicolumn{3}{c}{ Region } \\
\cline { 2 - 4 } & $\begin{array}{c}\text { Hippocampus } \\
\text { (CA3) }\end{array}$ & $\begin{array}{c}\text { Cortex } \\
\text { (parietal) }\end{array}$ & $\begin{array}{c}\text { Raphe nu } \\
\text { (dorsal) }\end{array}$ \\
\hline Male $(n=6)$ & $510 \pm 14^{\mathbf{a}}$ & $331 \pm 16$ & $2343 \pm 170$ \\
F-estrus $(n=8)$ & $494 \pm 14$ & $322 \pm 13$ & $2377 \pm 126$ \\
$\begin{array}{l}\text { F-diestrus } \\
(n=12)\end{array}$ & $473 \pm 13$ & $313 \pm 15$ & $2370 \pm 154$ \\
F-proestrus & $475 \pm 17$ & $319 \pm 5$ & $2084 \pm 126$ \\
$(n=8)$ & & & \\
\hline
\end{tabular}

Abbreviations: F, female; $\left.\left[{ }^{3} \mathrm{H}\right]-\mathrm{CN}-\mathrm{IMI},{ }^{3} \mathrm{H}\right]$-cyanoimipramine.

Data are expressed as femtomoles/mg protein.

aEach value is mean \pm SEM

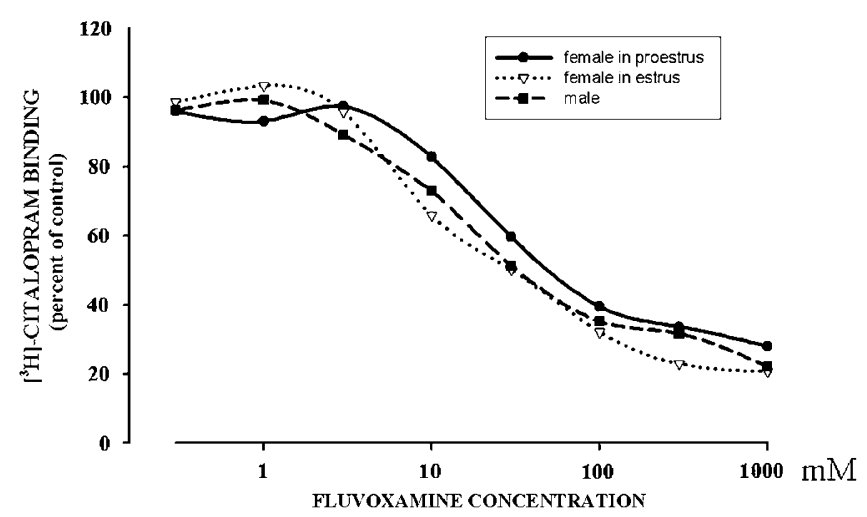

Figure 3 Representative data illustrating the potency of fluvoxamine to displace $\left[{ }^{3} \mathrm{H}\right]$ citalopram $(5 \mathrm{nM})$ binding to hippocampal membranes prepared from female rats in proestrus or estrus or from male rats. In each experiment, each point is calculated in triplicate. The number of rats (n) was 9 for male, 5 for estrus, and 5 for proestrus. Displacement curves show that the ability of fluvoxamine to displace $\left[{ }^{3} \mathrm{H}\right]$ citalopram binding was similar in males and females in proestrus or estrus.

IMI binding $(1 \mathrm{nM})$. This ligand concentration is about $8 \times$ the $K_{\mathrm{D}}$ value for $\left[{ }^{3} \mathrm{H}\right]-\mathrm{CN}$-IMI (Kovachich et al, 1988) so that SERT densities obtained approximate $\mathrm{B}_{\max }$ values. Specific binding in several brain areas was quantified in males or in females in proestrus, estrus, or diestrus, and the data are presented in Table 1. SERT binding sites were similar in males and females in all the areas analyzed. There was no fluctuation in binding sites in females during the estrous cycle.

The ability of fluvoxamine to block 5-HT clearance was reduced in female rats in proestrus as compared with that in female rats in estrus or male rats (Figures 1 and 2). This effect could result from a lower affinity (ie, higher $K_{\mathrm{i}}$ value) of fluvoxamine for SERT binding sites in rats in proestrus as compared with that in the two other groups. To test this hypothesis, the potency of fluvoxamine to displace $\left[{ }^{3} \mathrm{H}\right] \mathrm{ci}-$ talopram $(5 \mathrm{nM})$ binding to hippocampal membranes prepared from female rats in proestrus or estrus or in male rats was measured. The ability of fluvoxamine to displace $\left[{ }^{3} \mathrm{H}\right]$ citalopram binding was similar in males and in females in proestrus or in estrus (Figure 3). Comparison of 
fluvoxamine's $\quad K_{\mathrm{i}} \quad$ values $\quad(3.84 \pm 0.56 ; \quad 3.43 \pm 0.34$; $3.33 \pm 0.40 \mathrm{nM}$ for males $(n=9)$; females in estrus $(n=5)$, or in proestrus $(n=5)$, respectively) showed no differences between these groups (see details for calculation under Materials and Methods). Thus, the potency of fluvoxamine to compete for SERT-binding sites was similar in female rats in proestrus or estrus or in male rats.

\section{Effects of Acute Ovarian Hormone Treatments on SERT Function and on the Effect of Fluvoxamine}

Many parameters change during the estrus cycle in addition to circulating levels of estrogen or progesterone. To evaluate whether results obtained in female rats in proestrus were due to the influence of estrogen and/or progesterone on SERT function, OVX rats were treated with either EB and/or P. Concentrations of hormones in the serum were measured in order to verify that the hormone treatment regimen achieved estrogen and progesterone plasma levels characterized in proestrus. Mean $( \pm$ SEM) serum levels of estradiol $\left(\mathrm{E}_{2}=52.7 \pm 14.21 \mathrm{pg} / \mathrm{ml}\right)$ and progesterone $(\mathrm{P}=11.2 \pm 1.91 \mathrm{ng} / \mathrm{ml})$ were measured by RIA after administration of the combination treatment $\mathrm{EB} / \mathrm{P} \quad(n=6)$. Control rats $(n=4)$ received similar injections of peanut oil $\left(\mathrm{E}_{2}=8.5 \pm 1.68 \mathrm{pg} / \mathrm{ml} ; \mathrm{P}=2.5 \pm 1.24 \mathrm{ng} / \mathrm{ml}\right)$. During the estrus cycle, $\mathrm{E}_{2}$ peak levels of about $50 \mathrm{pg} / \mathrm{ml}$ occur in $\mathrm{pm}$ proestrus (Gibbs, 1996); this is in good agreement with the $\mathrm{E}_{2}$ level found. Values for $\mathrm{P}$ are, if anything, somewhat lower than those found in proestrus.

The ability of fluvoxamine to modulate 5-HT clearance in these groups of rats is shown in Figure 4a. In control OVX rats, the clearance time parameter, $T_{80}$, was significantly increased by local application of fluvoxamine even though the clearance rate parameter, $T_{\mathrm{C}}$, was not (Figure $4 \mathrm{a}$ and $\mathrm{b}$ ). However, the ability of fluvoxamine to prolong the clearance time of serotonin was abolished by either EB or $P$ treatment alone or by the combination of the two hormones. Similarly, local application into the CA3 region of another SSRI, citalopram, increased $T_{80}$ value $(169 \pm 15 \%$ of the pre-citalopram value) in OVX-control rats $(n=4)$. This effect was blocked in OVX rats treated with $\mathrm{EB} / \mathrm{P}$ ( $n=4, T_{80}$ value post-citalopram was $112 \pm 8 \%$ of the precitalopram value).

In addition, EB treatment increased baseline (ie, prefluvoxamine) $T_{80}$ value and decreased clearance rate, $T_{C}$, significantly from that measured in OVX rats (Figure $4 \mathrm{~b}$ ). The other treatment paradigms did not produce this effect.

To determine whether the effects of hormones are gender specific, castrated male rats were treated with $\mathrm{EB} / \mathrm{P}$, as described under Materials and Methods, and the effect of locally applied fluvoxamine was analyzed. $T_{80}$ values in castrated rats treated with vehicle: $73 \pm 12 \mathrm{~s}$ pre- and $108 \pm 16 \mathrm{~s}$ post-fluvoxamine were similar to those measured in castrated male treated with EB/P $(81 \pm 11 \mathrm{~s}$ pre- and $123 \pm 13 \mathrm{~s}$ post-fluvoxamine) The effect of fluvoxamine on $T_{80}$ was significant $(p<0.01$, paired $t$-test $)$ and of similar magnitude in the two groups. Thus, the inhibitory effect of fluvoxamine on SERT function in castrated male rats was not affected by treatment with $\mathrm{EB} / \mathrm{P}$ as it was in ovariectomized female rats.
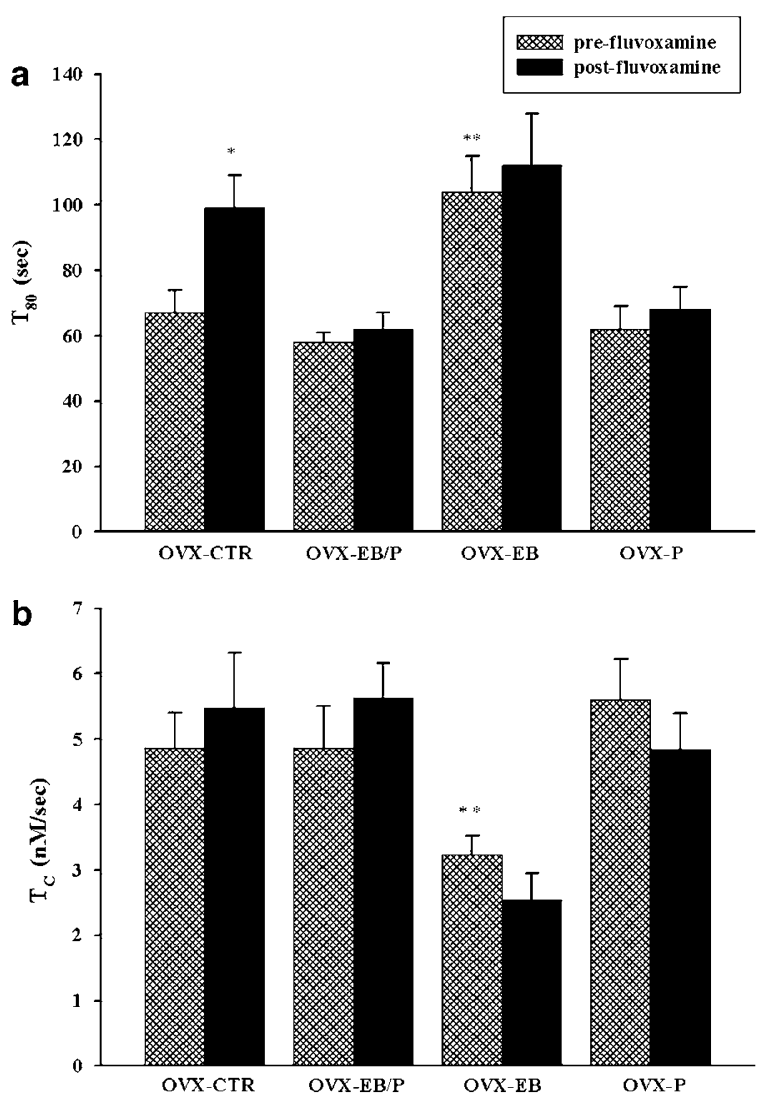

Figure 4 Effects of fluvoxamine on the clearance time, $T_{80}$, and clearance rate, $T_{C}$, in OVX rats treated with ovarian hormones. Electrochemical recordings were performed in the CA3 region of dorsal hippocampus of $O V X$ rats treated with $E B, P$, the combination $E B / P$, or peanut oil, as described under Materials and Methods. Fluvoxamine was pressure-ejected 60-90 s before the second application of 5-HT. (a) Bars and brackets represent mean $T_{80}$ values (in seconds) before and after fluvoxamine application; \pm SEM $(n=7-9)$. (b) Bars and brackets represent mean $T_{C}$ values (in $\mathrm{nM} / \mathrm{s}$ ) before and after fluvoxamine application; \pm SEM $(n=7-9)$. $* p<0.05$, paired Student's $t$-test comparing each group's pre-fluvoxamine value with its post-fluvoxamine value. $* * * 0.05$, Newman-Keuls comparing pre-fluvoxamine values for OVX hormones-treated with OVX-CTR. In this experiment too, the amount of $5-\mathrm{HT}$ ejected was adjusted so as to obtain comparable signal amplitudes $(0.25-0.4 \mu \mathrm{M})$ in the various groups of animals, as described in the legend to Figure 2. The mean amount of 5-HT in pmoles \pm SEM pressure ejected in each group was not significantly different between groups and was as follows: OVX-CTR, $4.1 \pm 1$; OVX-EB $+\mathrm{P}, 9.8 \pm 3$; OVX-EB, $6.4 \pm 2$; and OVX-P, $4.2 \pm 2$

\section{Time Course of the Effect of Local Application of $17-\beta$-Estradiol on the Effect of Fluvoxamine}

In this experiment, the time course of the effect of direct local application of $E_{2}$ into the $C A 3$ region of the hippocampus on fluvoxamine's blockade of 5-HT clearance was investigated in OVX rats. Fluvoxamine's ability to block 5-HT clearance was examined from 1 to $120 \mathrm{~min}$ after local application of $\mathrm{E}_{2}$ (10 or 57 pmoles) or PBS as the control vehicle. Changes in the $T_{80}$ value obtained after application of fluvoxamine are presented in Figure 5a. Vehicle-treated rats or those administered various amounts of $E_{2}$ had the effect of fluvoxamine measured both prior to hormone administration (the time 0 value in Figure 5) as well as afterwards. The effect of fluvoxamine was consistent 


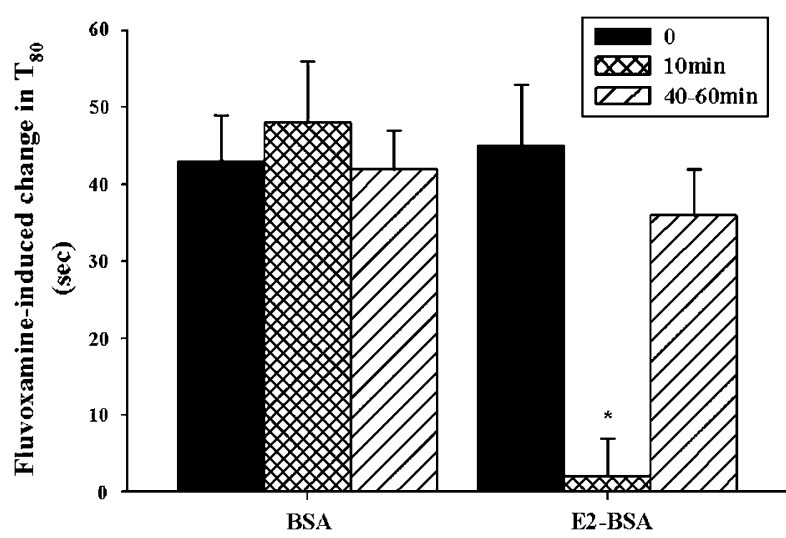

Figure 6 Effects of the $E_{2}-B S A$ conjugate on fluvoxamine's ability to increase 5-HT clearance time. The ability of fluvoxamine to increase $T_{80}$ was examined at time 0 (before application of $E_{2}-B S A$ or BSA alone) or 10 or 40-60 min after local application of BSA or $E_{2}-B S A$ (calculated so as to contain 20 pmoles $E_{2}$ ). Bars and brackets represent the increase in $T_{80}$ values (in seconds) after the application of fluvoxamine; \pm SEM $(n=6-8)$. $* p<0.05$, paired $t$-test comparing the increase in $T_{80}$ after fluvoxamine application for each post-drug treatment with the corresponding value before drug treatment.

of $E_{2}$. The lower amount of $E_{2}$ (10 pmoles) had no effect on fluvoxamine's ability to inhibit 5-HT clearance at either early or later time points (Figure 5a). Preliminary experiments carried out with 20 pmoles of $\mathrm{E}_{2}$ generated data similar to that seen with 57 pmoles (data not shown).

To determine whether this inhibitory effect of local application of $\mathrm{E}_{2}$ is mediated by membrane or intracellular ERs, two ER antagonists (tamoxifen and ICI 182,780; Xiao et al, 2003) were tested. In addition, the effect of a membrane impermeable estradiol-BSA conjugate $\left(\mathrm{E}_{2}-\right.$ BSA) (Blackmore and Lattanzio, 1991; Ramirez and Zheng, 1996) was measured as well. The drugs were given $10 \mathrm{~min}$ prior to addition of $E_{2}$ and their effects were measured either shortly $(10 \mathrm{~min})$ or at later times $(40-60 \mathrm{~min})$ after administration of $\mathrm{E}_{2}$ or $\mathrm{E}_{2}-\mathrm{BSA} . \mathrm{E}_{2}$ was used at 20 pmol in these experiments, as it was the minimum effective dose for both rapid (1-10 min) and later developing effects (30-60 min). As expected, $\mathrm{E}_{2}$ alone blocked the ability of fluvoxamine to induce an increase in the clearance time for 5 - $\mathrm{HT}$ at $10 \mathrm{~min}$ as well as at 40 60 min post- $\mathrm{E}_{2}$ (Figure $5 \mathrm{~b}$ ). Both ICI 182,780 and tamoxifen blocked this inhibitory effect of $E_{2}$ at $10 \mathrm{~min}$. The effect of ICI 182,780 persisted at $40-60 \mathrm{~min}$, whereas the inhibitory effect of tamoxifen was no longer observed at this time (Figure 5b). Local application of $\mathrm{E}_{2}$ - $\mathrm{BSA}$ abolished the fluvoxamine-induced increase in the $T_{80}$ value only at the early time point (10 min after $\mathrm{E}_{2}-\mathrm{BSA}$ application) and not at the later time, 40-60 min (Figure 6). BSA alone had no effect on the ability of fluvoxamine to increase $T_{80}$ value (Figure 6).

\section{DISCUSSION}

These results show that the ability of fluvoxamine to inhibit clearance time of 5-HT in vivo is markedly diminished in female rats during proestrus. This is not due to proestrus 
lowering the affinity of fluvoxamine for the SERT. This effect of proestrus seems to be due either to estrogen and/or progesterone, as administration of either hormone to OVX rats, but not to castrated male rats, produced effects similar to those seen in proestrus. In addition, estradiol alone altered 5-HT clearance rate. Results obtained from local application of $E_{2}, E_{2}$-BSA and ER antagonists directly into the CA3 region of the hippocampus indicates that both intracellular as well as membrane ERs may be involved in the ability of $E_{2}$ to inhibit the effect of fluvoxamine.

The hippocampus is an appropriate area to study the interaction between ovarian steroids and SSRIs on SERT function. There are considerable data demonstrating a role for the hippocampus in the pathophysiology of depression (Campbell and Macqueen, 2004), particularly with respect to changes in hippocampal volume (Campbell et al, 2004). The hippocampus receives a dense serotonergic innervation (Jacobs and Azmitia, 1992) and it is the initial increase in either 5-HT and/or NE caused by ADs that is thought to trigger changes responsible for their beneficial clinical effects (Delgado et al, 1999; Miller et al, 1996). The increase in 5-HT is due to the inhibition of the SERT, the initial cellular target for SSRIs (Lenox and Frazer, 2002). Finally, the hippocampus is an estrogen responsive area in the brain, with humans containing mRNAs for both $\mathrm{ER} \alpha$ and $\operatorname{ER} \beta$ (Osterlund et al, 2000a, b).

The detection of neurotransmitter injected into brain by a sensor located some distance from the site of injection is a complex phenomenon. Factors that influence the shape of the signals detected include not only uptake of the transmitter, but also its diffusion in obstructed extracellular space (Nicholson and Phillips, 1981), as well as, perhaps, metabolism. The clearance time parameter $\left(T_{80}\right)$ used to quantitatively analyze the serotonin electrochemical signal was selected because it is known to reflect primarily the uptake process rather than metabolism or diffusion and also it clearly and reproducibly detects effects of locally applied competitive uptake inhibitors (Benmansour et al, 1999, 2002; Cass et al, 1993; Hoffman and Gerhardt, 1998; Zahniser et al, 1999). Whereas local application of uptake inhibitors have consistent and significant effects on clearance time parameters, they do not consistently alter clearance rates as measured using in vivo chronoamperometry, even though it might be expected that they would. In a very careful study, the clearance of dopamine by the dopamine transporter (DAT) was shown to be altered by local application of inhibitors of the DAT, with the effect being dependent on the initial basal amplitude of the DA signal (Zahniser et al, 1999). Perhaps not surprisingly, the most pronounced increase in $T_{80}$ caused by uptake inhibitors was found at the lowest basal amplitude. The effects of DAT inhibitors on clearance rate were less consistent, but there were trends for clearance rate to increase in the low basal amplitude group, to decrease in the high basal amplitude group, and not to change in the medium basal amplitude group. None of these effects were statistically significant. Thus, although one might expect clearance rate to change, it does not after local application of uptake inhibitors. Why this is so is not clear. With local application of drugs, it is difficult to predict the concentration achieved and consequently the occupancy of the SERT; this is especially so, as local application of drugs does not allow steady state to develop. Further, we are not using concentrations of 5-HT that saturate the SERT (Daws et al, 2005). It is well established that local application of SSRIs raises extracellular 5-HT (eg, Kreiss and Lucki, 1995). Consequently, when sub-saturating concentrations of both 5-HT and SSRIs are present, the rate of uptake of 5-HT by SERT not occupied by SSRIs would be expected to increase due to elevated 5-HT. Thus an expected decrease in clearance rate by SERT that is occupied by SSRIs may be compensated by an increase in clearance rate by those not occupied.

During proestrus or following treatment of OVX rats with estradiol or progesterone either alone or in combination, fluvoxamine no longer increased clearance time for exogenously administered 5-HT (Figures 2 and 4). These hormonal effects could possibly reflect a conformational change in the transporter that reduces the accessibility of inhibitors to the binding site. The clearance time parameter, $T_{80}$, was increased after treatment with EB (Figure 4). This effect was similar to that obtained after local application of fluvoxamine in OVX-control rats. Such an effect of estradiol might account, at least in part, for the observation that depression may be more common when estradiol levels are low (Fink et al, 1996; Halbreich et al, 1992; Pearlstein, 1995) and that estrogen can have $\mathrm{AD}$ effects (Zweifel and O'Brien, 1997; Soares et al, 2001; Huttner and Shepherd, 2003). However, it is difficult to reconcile this effect of estrogen with the higher incidence of depression in women (Kessler, 2003). Further adding estrogen therapy to SSRI treatment may be beneficial in depressed menopausal women (Yonkers, 2003). Yet our data shows that estrogen, at least when given acutely, inhibits the inhibitory effect of SSRIs on SERT function, which is not consistent with such a clinical effect. Further research examining the effect of more chronic treatment with hormones on SERT function and the effect of SSRIs on such function should help to clarify such issues.

Treatment with EB not only increased clearance time parameters, but also reduced the clearance rate for 5-HT (Figure 4). Estrogen can act at several levels of the serotonergic system. For example, it can inhibit reuptake by monoaminergic transporters in vitro (Michel et al, 1987). Also, estrogen has been shown to interact with either 5$\mathrm{HT}_{1 \mathrm{~A}}$ or $5 \mathrm{HT}_{2 \mathrm{~A}}$ receptors in several brain areas (Fink et al, 1996; Osterlund et al, 1999; Raap et al, 2000). The present study shows that estrogen not only blocked the ability of an SSRI to induce prolongation of the 5-HT signal, but also decreased SERT function (Figure 4). These changes could be interpreted as a result of an EB-induced change in the affinity of the SERT for 5-HT. EB could have induced a change in the phosphorylation state of the SERT and/or changes in protein association (ie, syntaxin $1 \mathrm{~A}, \mathrm{PP} 2 \mathrm{Ac}$ ) that could support changes in SERT trafficking and catalytic modulation (Blakely et al, 2005). On the other hand, EB treatment could have induced changes in the characteristics of the extracellular space (ie, tortuosity) such that pressureejected 5-HT is 'moving slower' both to reach the electrode tip and to be removed from it. This is, however, unlikely, since the rise time of the 5-HT signal was not increased in EB-treated OVX rats (data not shown). Furthermore, the experiment carried out with treated with EB castrated rats showing blockade of 5-HT clearance after fluvoxamine 
application is yet another argument in favor of the specificity of the effect of hormones.

Gender differences exist in many of the actions of estrogen in the brain, and the process of sexual differentiation appears to affect many brain regions outside of the traditional brain areas involved in the reproductive function (McEwen, 2001). Our data show that treatment of castrated rats with the combination $\mathrm{EB} / \mathrm{P}$ did not alter the ability of fluvoxamine to increase the $T_{80}$ value of 5 -HT clearance, whereas treatment of OVX rats with EB/P blocked fluvoxamine induced increase in $T_{80}$. Thus, the modulations by ovarian hormones on the SSRI-SERT interaction are gender specific. It was shown that estradiol was able to affect SERT expression in female as well as male rat brain (McQueen et al, 1999). It is possible that the differences are due to the treatment protocol (hormonal treatment 2 weeks after gonadectomy as opposed to treatment immediately after gonadectomy, as well as time of hormonal acute exposure (72 h as opposed to $36 \mathrm{~h})$ ).

Our data indicate that progesterone, similar to estrogen, blocked fluvoxamine's ability to prolong the 5-HT signal (Figure 4). This finding is consistent with other studies showing that not only estradiol but also progesterone can alter serotonergic neurotransmission. A stimulatory role for progesterone in the regulation of 5-HT synthesis has been demonstrated (Jahn and Deis, 1987), even though progesterone appears to have no effect on the translation of the serotonin-synthesizing enzyme, tryptophan hydroxylase (Bethea et al, 2000). Our data show that progesterone, similar to estrogen, interferes with the ability of an SSRI to block SERT function. Progesterone however had no effect on basal SERT function.

The analysis of SERT binding site densities indicates no change during the rat estrous cycle (Table 1 ). $\left[{ }^{3} \mathrm{H}\right]-\mathrm{CN}-\mathrm{IMI}$ is a lipophilic ligand and could label not only membrane SERT but intracellular SERT as well. The number of SERTs located on the plasma membrane is controlled through kinase- and phosphatase-linked pathways, as shown in transfected cells (Qian et al, 1997; Ramamoorthy and Blakely, 1999; Ramamoorthy et al, 1998). Recently, in an elegant study using surface biotinylation of purified synaptosomes from rat midbrain, a reduction of the fraction of cell-surface expression of SERT protein in the plasma membrane of synaptosomes following either protein kinase $\mathrm{C}$ activation or p38 mitogen-activated protein kinase was demonstrated (Samuvel et al, 2005). Therefore, a redistribution of SERT from the intracellular pool to the membrane surface could result from treatment with EB. This hypothesis remains to be tested.

Using in vivo voltammetry, it was shown that local application of $E_{2}$ into the nucleus accumbens of OVX rats induced rapid modulation of dopamine activity (Thompson and Moss, 1994). Consistent with this, the time course of the effect of locally applied $\mathrm{E}_{2}$ into the $\mathrm{CA} 3$ region of the hippocampus of OVX rats showed that fluvoxamine's ability to block the clearance of 5-HT was abolished as early as 110 min after $E_{2}$ application as well as at later time points (20-60 min) (Figure 5). Data obtained after local application of the membrane-impermeable $\mathrm{E}_{2}-\mathrm{BSA}$ conjugate provide further support for the involvement of membrane ERs, since it mimicked only the early effects obtained after $E_{2}$ application (Figure 6). Modulation of fluvoxamine's ability to block 5-HT clearance by $\mathrm{E}_{2}$ was blocked by ER antagonists. ICI 182,780 blocked the effects of $\mathrm{E}_{2}$ at early as well as at later time points, whereas tamoxifen blocked only the early effect of $E_{2}$. It is possible that tamoxifen was removed from the hippocampus faster than ICI 182,780 , or that the concentration used did not antagonize intracellular ER. These data indicate that the $E_{2}$-induced blockade of fluvoxamine's effects on SERT is likely mediated via genomic as well as non-genomic mechanisms.

In conclusion, the main finding of the present study demonstrates that acute treatment with either EB or $\mathrm{P}$ impacts the ability of SSRIs to alter the function of what is widely considered their initial cellular target - the SERT. There is at least one interesting potential clinical implication of these data. Although pharmacotherapy of depression with SSRIs or other drugs is more effective than treatment with placebo, $50-70 \%$ of patients have less than optimal to no response to an initial trial with an AD (Fava et al, 2006; Rush et al, 2006; Trivedi et al, 2006). If hormones such as estrogen or progesterone reduce the ability of SSRIs to block the SERT, then some patients may be, for genetic reasons, unusually sensitive to such hormonal effects, which could contribute to non-response.

\section{ACKNOWLEDGEMENTS}

This work was supported by funds from NARSAD and the Department of Veterans Affairs. We thank Dr Andrea Gore for help with analysis of hormones levels and Kelly Sharp and Dr Georgianna Gould for technical assistance.

\section{DISCLOSURE/CONFLICT OF INTEREST}

Dr Benmansour, Mr Piotrowski, and Mr Altamirano report no biomedical financial interests or potential conflicts of interest. Dr Frazer reports that he has been on advisory boards for Cyberonics Inc. and H Lundbeck A/S and that he has consulted and/or received research support for preclinical studies from Forest Research Institute, Eli Lilly and Company, and Wyeth Pharmaceuticals, but no support for this study was received by any pharmaceutical company.

\section{REFERENCES}

Adams MM, Morrison JH, Gore AC (2001). N-methyl-D-aspartate receptor mRNA levels change during reproductive senescence in the hippocampus of female rats. Exp Neurol 1701: 171-179.

Attali G, Weizman A, Gil-Ad I, Rehavi M (1997). Opposite modulatory effects of ovarian hormones on rat brain dopamine and serotonin transporters. Brain Res 7561-2: 153-159.

Benmansour S, Cecchi M, Morilak DA, Gerhardt GA, Javors MA, Gould GG et al (1999). Effects of chronic antidepressant treatments on serotonin transporter function, density, and mRNA level. J Neurosci 1923: 10494-10501.

Benmansour S, Owens WA, Cecchi M, Morilak DA, Frazer A (2002). Serotonin clearance in vivo is altered to a greater extent by antidepressant-induced downregulation of the serotonin transporter than by acute blockade of this transporter. J Neurosci 2215: 6766-6772.

Bethea CL, Gundlah C, Mirkes SJ (2000). Ovarian steroid action in the serotonin neural system of macaques. Novartis Found Symp 230: 112-130, discussion 130-133. 
Bethea CL, Pecins-Thompson M, Schutzer WE, Gundlah C, Lu ZN (1998). Ovarian steroids and serotonin neural function. Mol Neurobiol 182: 87-123.

Blackmore PF, Lattanzio FA (1991). Cell surface localization of a novel non-genomic progesterone receptor on the head of human sperm. Biochem Biophys Res Commun 1811: 331-336.

Blakely RD, Defelice LJ, Galli A (2005). Biogenic amine neurotransmitter transporters: just when you thought you knew them. Physiology (Bethesda) 20: 225-231.

Bradford MM (1976). A rapid and sensitive method for the quantitation of microgram quantities of protein utilizing the principle of protein-dye binding. Anal Biochem 72: 248-254.

Burt VK, Stein K (2002). Epidemiology of depression throughout the female life cycle. J Clin Psychiatry 63(Suppl 7): 9-15.

Campbell S, Macqueen G (2004). The role of the hippocampus in the pathophysiology of major depression. J Psychiatry Neurosci 296: 417-426.

Campbell S, Marriott M, Nahmias C, MacQueen GM (2004). Lower hippocampal volume in patients suffering from depression: a meta-analysis. Am J Psychiatry 1614: 598-607.

Cass WA, Zahniser NR, Flach KA, Gerhardt GA (1993). Clearance of exogenous dopamine in rat dorsal striatum and nucleus accumbens: role of metabolism and effects of locally applied uptake inhibitors. J Neurochem 616: 2269-2278.

D'Amato RJ, Largent BL, Snowman AM, Snyder SH (1987). Selective labeling of serotonin uptake sites in rat brain by $[3 \mathrm{H}]$ citalopram contrasted to labeling of multiple sites by [3H]imipramine. J Pharmacol Exp Ther 2421: 364-371.

Daws LC, Montanez S, Owens WA, Gould GG, Frazer A, Toney GM et al (2005). Transport mechanisms governing serotonin clearance in vivo revealed by high-speed chronoamperometry. J Neurosci Methods 143: 49-62.

Delgado PL, Miller HL, Salomon RM, Licinio J, Krystal JH, Moreno FA et al (1999). Tryptophan-depletion challenge in depressed patients treated with desipramine or fluoxetine: implications for the role of serotonin in the mechanism of antidepressant action. Biol Psychiatry 462: 212-220.

Fava M, Rush AJ, Wisniewski SR, Nierenberg AA, Alpert JE, McGrath PJ et al (2006). A comparison of mirtazapine and nortriptyline following two consecutive failed medication treatments for depressed outpatients: a $\mathrm{STAR}^{\star} \mathrm{D}$ report. $A m \mathrm{~J}$ Psychiatry 1637: 1161-1172.

Fink G, Sumner BE, Rosie R, Grace O, Quinn JP (1996). Estrogen control of central neurotransmission: effect on mood, mental state, and memory. Cell Mol Neurobiol 163: 325-344.

Gibbs RB (1996). Fluctuations in relative levels of choline acetyltransferase mRNA in different regions of the rat basal forebrain across the estrous cycle: effects of estrogen and progesterone. J Neurosci 163: 1049-1055.

Gore AC, Yeung G, Morrison JH, Oung T (2000). Neuroendocrine aging in the female rat: the changing relationship of hypothalamic gonadotropin-releasing hormone neurons and $\mathrm{N}$-methylD-aspartate receptors. Endocrinology 14112: 4757-4767.

Halbreich U, Piletz J, Halaris A (1992). Influence of gonadal hormones on neurotransmitters, receptor, cognition and mood. Clin Neuropharmacol 15(Suppl 1 Part A): 590A-591A.

Hoffman AF, Gerhardt GA (1998). In vivo electrochemical studies of dopamine clearance in the rat substantia nigra: effects of locally applied uptake inhibitors and unilateral 6-hydroxydopamine lesions. J Neurochem 701: 179-189.

Huttner RP, Shepherd JE (2003). Gonadal steroids, selective serotonin reuptake inhibitors, and mood disorders in women. Med Clin North Am 875: 1065-1076.

Jacobs BL, Azmitia EC (1992). Structure and function of the brain serotonin system. Physiol Rev 721: 165-229.

Jahn GA, Deis RP (1987). A possible dual regulation of prolactin release by the serotoninergic system in rats at pro-oestrus and during late pregnancy: role of ovarian hormones. J Endocrinol 1123: 367-374.

Katzenellenbogen BS (2000). Mechanisms of action and cross-talk between estrogen receptor and progesterone receptor pathways. J Soc Gynecol Investig 71(Suppl): S33-S37.

Kelly MJ, Lagrange AH, Wagner EJ, Ronnekleiv OK (1999). Rapid effects of estrogen to modulate $G$ protein-coupled receptors via activation of protein kinase $\mathrm{A}$ and protein kinase $\mathrm{C}$ pathways. Steroids 641-2: 64-75.

Kessler RC (2003). Epidemiology of women and depression. J Affect Disord 741: 5-13.

Kornstein SG, Schatzberg AF, Thase ME, Yonkers KA, McCullough JP, Keitner GI et al (2000). Gender differences in treatment response to sertraline $v s$ imipramine in chronic depression. Am J Psychiatry 1579: 1445-1452.

Kovachich GB, Aronson CE, Brunswick DJ, Frazer A (1988). Quantitative autoradiography of serotonin uptake sites in rat brain using $[3 \mathrm{H}]$ cyanoimipramine. Brain Res 4541-2: 78-88.

Krajnak K, Rosewell KL, Duncan MJ, Wise PM (2003). Aging, estradiol and time of day differentially affect serotonin transporter binding in the central nervous system of female rats. Brain Res 9901-2: 87-94.

Kreiss DS, Lucki I (1995). Effects of acute and repeated administration of antidepressant drugs on extracellular levels of 5-hydroxytryptamine measured in vivo. J Pharmacol Exp Ther 274: $866-876$

Lenox RH, Frazer A (2002). Mechanism of Action of Antidepressants and Mood-Stabilizers. Lippincott Williams \& Wilkins: Philadelphia.

McEwen BS (2001). Invited review: estrogens effect on the brain: multiple sites and molecular mechanisms. J Appl Physiol 91: 2785-2801.

McQueen JK, Wilson H, Fink G (1997). Estradiol-17 beta increases serotonin transporter (SERT) mRNA levels and the density of SERT-binding sites in female rat brain. Brain Res Mol Brain Res 451: $13-23$.

McQueen JK, Wilson H, Sumner BE, Fink G (1999). Serotonin transporter (SERT) mRNA and binding site densities in male rat brain affected by sex steroids. Brain Res Mol Brain Res 63: 241-247.

Mendelson SD, McKittrick CR, McEwen BS (1993). Autoradiographic analyses of the effects of estradiol benzoate on $[3 \mathrm{H}]$ paroxetine binding in the cerebral cortex and dorsal hippocampus of gonadectomized male and female rats. Brain Res 6011-2: 299-302.

Michel MC, Rother A, Hiemke C, Ghraf R (1987). Inhibition of synaptosomal high-affinity uptake of dopamine and serotonin by estrogen agonists and antagonists. Biochem Pharmacol 3619: 3175-3180.

Miller HL, Delgado PL, Salomon RM, Berman R, Krystal JH, Heninger GR et al (1996). Clinical and biochemical effects of catecholamine depletion on antidepressant-induced remission of depression. Arch Gen Psychiatry 532: 117-128.

Nadal A, Ropero AB, Laribi O, Maillet M, Fuentes E, Soria B (2000). Nongenomic actions of estrogens and xenoestrogens by binding at a plasma membrane receptor unrelated to estrogen receptor alpha and estrogen receptor beta. Proc Natl Acad Sci USA 9721: 11603-11608.

Nicholson C, Phillips JM (1981). Ion diffusion modified by tortuosity and volume fraction in the extracellular microenvironment of the rat cerebellum. J Physiol 321: 225-257.

Osterlund MK, Grandien K, Keller E, Hurd YL (2000a). The human brain has distinct regional expression patterns of estrogen receptor alpha mRNA isoforms derived from alternative promoters. J Neurochem 754: 1390-1397.

Osterlund MK, Gustafsson JA, Keller E, Hurd YL (2000b). Estrogen receptor beta (ERbeta) messenger ribonucleic acid (mRNA) expression within the human forebrain: distinct distribution pattern to ERalpha mRNA. J Clin Endocrinol Metab 8510: 3840-3846. 
Osterlund MK, Overstreet DH, Hurd YL (1999). The flinders sensitive line rats, a genetic model of depression, show abnormal serotonin receptor mRNA expression in the brain that is reversed by 17beta-estradiol. Brain Res Mol Brain Res 741-2: 158-166.

Paxinos G, Watson C (1986). The Rat Brain in Stereotaxic Coordinates. Academic: New York, NY.

Pearlstein TB (1995). Hormones and depression: what are the facts about premenstrual syndrome, menopause, and hormone replacement therapy? Am J Obstet Gynecol 1732: 646-653.

Pecins-Thompson M, Brown NA, Bethea CL (1998). Regulation of serotonin re-uptake transporter mRNA expression by ovarian steroids in rhesus macaques. Brain Res Mol Brain Res 531-2: 120-129.

Qian Y, Galli A, Ramamoorthy S, Risso S, DeFelice LJ, Blakely RD (1997). Protein kinase C activation regulates human serotonin transporters in HEK-293 cells via altered cell surface expression. J Neurosci 171: 45-57.

Quitkin FM, Stewart JW, McGrath PJ, Taylor BP, Tisminetzky MS, Petkova E et al (2002). Are there differences between women's and men's antidepressant responses? Am J Psychiatry 15911: 1848-1854.

Raap DK, DonCarlos L, Garcia F, Muma NA, Wolf WA, Battaglia G et al (2000). Estrogen desensitizes 5-HT(1A) receptors and reduces levels of $\mathrm{G}(\mathrm{z}), \mathrm{G}(\mathrm{i} 1)$ and $\mathrm{G}(\mathrm{i} 3)$ proteins in the hypothalamus. Neuropharmacology 3910: 1823-1832.

Ramamoorthy S, Blakely RD (1999). Phosphorylation and sequestration of serotonin transporters differentially modulated by psychostimulants. Science 285: 763-766.

Ramamoorthy S, Melikian HE, Qian Y, Blakely RD (1998). Biosynthesis, $\mathrm{N}$-glycosylation, and surface trafficking of biogenic amine transporter proteins. Methods Enzymol 296: 347-370.

Ramirez VD, Zheng J (1996). Membrane sex-steroid receptors in the brain. Front Neuroendocrinol 174: 402-439.

Rush AJ, Trivedi MH, Wisniewski SR, Nierenberg AA, Stewart JW, Warden D et al (2006). Acute and longer-term outcomes in depressed outpatients requiring one or several treatment steps: a STAR ${ }^{\star D}$ report. Am J Psychiatry 163: 1905-1917.

Saletu B, Brandstatter N, Metka M, Stamenkovic M, Anderer P, Semlitsch HV et al (1995). Double-blind, placebo-controlled, hormonal, syndromal and EEG mapping studies with transdermal oestradiol therapy in menopausal depression. Psychopharmacology (Berl) 122: 321-329.

Samuvel DJ, Jayanthi LD, Bhat NR, Ramamoorthy S (2005). A role for p38 mitogen-activated protein kinase in the regulation of the serotonin transporter: evidence for distinct cellular mechanisms involved in transporter surface expression. J Neurosci 251: $29-41$.

Scheibe S, Preuschhof C, Cristi C, Bagby RM (2003). Are there gender differences in major depression and its response to antidepressants? J Affect Disord 753: 223-235.

Soares CN, Almeida OP, Joffe H, Cohen LS (2001). Efficacy of estradiol for the treatment of depressive disorders in perimenopausal women: a double-blind, randomized, placebo-controlled trial. Arch Gen Psychiatry 58: 529-534.

Stevis PE, Deecher DC, Suhadolnik L, Mallis LM, Frail DE (1999). Differential effects of estradiol and estradiol-BSA conjugates. Endocrinology 140: 5455-5458.

Thompson TL, Moss RL (1994). Estrogen regulation of dopamine release in the nucleus accumbens: genomic- and nongenomicmediated effects. J Neurochem 625: 1750-1756.

Trivedi MH, Fava M, Wisniewski SR, Thase ME, Quitkin F, Warden $\mathrm{D}$ et al (2006). Medication augmentation after the failure of SSRIs for depression. N Engl J Med 354: 1243-1252.

Xiao L, Jackson LR, Becker JB (2003). The effect of estradiol in the striatum is blocked by ICI 182,780 but not tamoxifen: pharmacological and behavioral evidence. Neuroendocrinology 774: 239-245.

Yonkers KA (2003). Special issues related to the treatment of depression in women. J Clin Psychiatry 64(Suppl 18): 8-13.

Zahniser NR, Larson GA, Gerhardt GA (1999). In vivo dopamine clearance rate in rat striatum: regulation by extracellular dopamine concentration and dopamine transporter inhibitors. J Pharmacol Exp Ther 2891: 266-277.

Zhou W, Koldzic-Zivanovic N, Clarke CH, de Beun R, Wassermann $\mathrm{K}$, Bury PS et al (2002). Selective estrogen receptor modulator effects in the rat brain. Neuroendocrinology 751: 24-33.

Zweifel JE, O'Brien WH (1997). A meta-analysis of the effect of hormone replacement therapy upon depressed mood. Psychoneuroendocrinology 22: 189-212. 